ACTA Pó́tica 39-1 • ENERO-JUNIO • 2018 • 17-43

doi: $10.19130 /$ iifl.ap.2018.1.813

\author{
RAÚL RODRÍGUEZ FREIRE \\ Pontificia Universidad Católica de Valparaíso \\ raul.rodriguez@pucv.cl
}

\title{
El VALOR DE LA TEORÍA. El INTELECTUAL COMO PRODUCTOR ${ }^{1}$ The Value of Theory. The Intellectual as a Producer
}

\begin{abstract}
A partir de la transformación de cada sujeto en un empresario de sí, este artículo reflexiona sobre las posibilidades y los límites del trabajo intelectual contemporáneo. Siguiendo a Walter Benjamin en su ensayo, "El autor como productor" se analiza la condición de obrero del intelectual universitario, sujeto a la medición constante. Ello dado que la circulación de lo que se denomina "teoría crítica" también se desarrolla como un mercado con sus propios productores y consumidores bajo la lógica de la teoría del valor esgrimida por Marx, con lo cual se abastece la acumulación de capital a medida que se lo critica. Empero, no se trata de condenar esta situación, sino de explicitar la ambivalencia del lugar del intelectual crítico bajo la condición universitaria neoliberal. La universidad, por tanto, sería uno de los terrenos principales de la resistencia, en donde el concepto de lo común y de medios alternativos de difusión del saber podrían esgrimirse como armas para librar la batalla en contra de mercantilización del pensamiento crítico.

PALABRAS CLAVE: lo común, universidad, trabajo intelectual, Walter Benjamin, modos de producción.
\end{abstract}

From the transformation of each subject into a self-employed entrepreneur, this article reflects on the possibilities and limits of contemporary intellectual work. Following Walter Benjamin in his essay, "The author as a producer", the condition of the university intellectual worker is analyzed, subject to constant measurement. This is because the circulation of what is called "critical theory" also develops as a market with its own producers and consumers under the logic of the theory of value wielded by Marx, which provides the accumulation of capital as He criticizes it. However, it is not a question of condemning this situation, but of making explicit the ambivalence of the place of the critical intellectual under the neoliberal university condition. The university, therefore, would be one of the main areas of resistance, where the concept of the communality and alternative means of spreading knowledge could be used as weapons to wage the battle against the commodification of critical thinking.

KEYWORDS: communality; university; intellectual work; Walter Benjamin; modes of production.

Fecha de recepción: 4 | IX | 2017 Fecha de aceptación: $27|\mathrm{X}| 2017$

${ }^{1}$ Este ensayo se inscribe en el marco de un proyecto titulado "Ficciones académicas. Representaciones del trabajo universitario en la literatura hispanoamericana del siglo XXI", financiado por FONDECYT, Chile (número 11150405) y es una versión reducida de un trabajo en curso y de mayor extensión titulado La condición intelectual. 
Con el flâneur, la intelectualidad se dirige al mercado. Cree ella que para observarlo, cuando en realidad es para encontrar comprador.

Walter Benjamin, Charles Baudelaire. Un lírico en la época del altocapitalismo (1938)

Hay que venderse antes de que ellos, quienes sean, pierdan el interés por comprarte.

Roberto Bolaño, “Los mitos de Cthulhu” (2002)

1. Esquemáticamente, se podría señalar que el modelo neoextractivista de la universidad neoliberal ha impuesto la metrología (fordista) como forma exclusiva para la valorización del trabajo intelectual (postfordista), lo que no es otra cosa que la valorización de nuestro aporte a la generación de plusvalía. De manera que el sometimiento a los indicadores relativos a la productividad académica (reducida a la cuantificación de publicaciones, al fast paper) se ha transformado en la vía casi exclusiva para conseguir becas, fondos para viajes o proyectos, crear o modificar programas, lograr ascensos, etc., con lo cual el trabajo concreto que por un buen tiempo se resistió a la subsunción real ha devenido abstracto. Producimos para grupos editoriales que publican libros destinados exclusivamente a las bibliotecas universitarias (libros que sobrepasan los 100 euros, por lo que a priori no están pensados más que como negocio) $\mathrm{y} / \mathrm{o}$ para los grupos que controlan las revistas en las que publicamos (y para las cuales además trabajamos gratis, evaluando), como Elsevier (que en 2016 facturó más de 2600 millones de euros, con un margen de beneficios cercano al 40\%) y Thompson Reuters. La lógica de ambas empresas consiste en generar "clientes cautivos" (los Estados), que prácticamente obligan a las universidades a comprar sus productos (libros, artículos, indicadores, etc.), bajo el supuesto de la excelencia que entrega la rigurosidad con la que operan, a la vez que se "incentiva" a los académicos a publicar en éstas y sólo en estas editoriales y revistas, a cambio de tener la posibilidad de competir por los fondos públicos que financiarán los artículos que volveremos a publicar en el mismo lugar. ${ }^{2}$

${ }^{2}$ Esta "rigurosidad" recientemente ha sido puesta en cuestión gracias a una investigación realizada por Marc A. Edwards y Siddhartha Roy, en la que demuestran que detrás de las empresas que manejan las revistas y editoriales en las que publicamos lo que hay 
Así que cada vez más nos asemejamos al "literato proletario de Leipzig, que produce libros - por ejemplo compendios de economía política [o ensayos sobre el valor de la teoría] — por encargo de su librero [Elsevier o Thompson Reuters]", con lo cual nos hemos transformado en "un trabajador productivo, por cuanto su [nuestra] producción está subsumida en el capital y no se lleva a cabo sino para valorizarlo" (Marx 2008: 84).

La expresión, cada vez más mencionada, "publica o muere", sintetiza la lógica tóxica que se apoderó de las universidades. Así que, bajo este escenario, no son pocos los que, cada vez con más fuerza y mayor resonancia, han comenzado a criticar la reducción de la producción intelectual al llamado "factor de impacto", factor que nos lleva a operar como si la relación publicación-cita pudiera medir efectivamente la "influencia" intelectual o académica, como si un ensayo sobre la ficción en Cervantes o una discusión sobre el trabajo improductivo debieran someterse a los mismos criterios evaluativos que los de las llamadas ciencias duras, como si debieran tener el mismo devenir que una investigación sobre las células в y su control sobre la aptitud de las células de linfoma impulsadas por MYC mediante la inhibición de GSK3 в o sobre la estructura cristalina de un receptor GLP-1 unido a un agonista peptídico. He destacado este "como si" porque la producción intelectual contemporánea se parece cada vez más a la producida en Tlön, donde el mero acto de clasificar (y, agregamos aquí, de indexar y medir) un hecho "importa un falseo" (Borges: 835), una impostura que los llamados "escándalos de la ciencia" (plagios, datos falsos, etc.), que van en aumento, no hacen sino confirmar. Si en Tlön "nadie cree en la realidad de los sustantivos", en la Tierra nadie cree en los sustantivos de la realidad universitaria: calidad, excelencia, rigurosidad, entre otros, son significantes vacíos que cada académico o institución usa a su antojo, pero siempre "sin contenido". Si en Tlön la filosofía es un juego, en la Tierra la ciencia es un negocio, una rama de la economía fantástica obliterando que la relevancia de las humanidades se da no en el momento de una publicación, sino a lo largo de su tiempo de circulación (piénsese en Walter Benjamin, que en su tiempo fue casi un descono-

es un modelo de negocio que ha perjudicado radicalmente la producción y circulación del saber, pues su preocupación no es otra que el dinero. Ver Edwards y Roy 2017: 51-61. 
cido y hoy es una referencia ineludible). Así las cosas, la medición (valorización) de nuestro trabajo ha llegado a obliterar la importancia que tiene el libro para quienes nos desempeñamos en el ámbito de la literatura o la filosofía, pues el modelo dominante es el de la promoción de los "descubrimientos" de las ciencias aplicadas, esos que llegan a tener hasta 20 autores (aunque jerárquicamente consignados), de los cuales algunos, sobre todo los directores de laboratorio, pueden "participar" en más de 20 publicaciones anuales o dividir el resultado de una investigación en tantas partes como sea posible. Y es lamentable que lo mismo se haya comenzado a hacer, si bien a regañadientes, desde las humanidades, pero como acá el trabajo es menos gregario, se recurre al plagio de estudiantes o colegas; se "presta" el nombre para una publicación en la que no se ha participado (a veces ambas cosas a la vez); se publica el mismo texto en varios idiomas; se publica a nombre propio o en "colaboración" el trabajo de los estudiantes; o, imitando (sin saberlo) a Borges, se cambia el título y el resumen para despistar a imaginarios lectores. Y, "en parte", se entiende, cuando la continuidad de un contrato laboral (precario o no) depende cada vez más de cuánto publicamos y de cómo, en consecuencia, se nos mide. Y eso nos molesta mucho. Por eso resulta tan sorprendente que millones de académicas y académicos de todo el mundo (y me incluyo, pues también estoy ahí) hayan creado libremente un perfil y subido sus trabajos al sitio web Academia.edu, una empresa que ha transformado la medición algorítmica en su principal forma de relacionarse con sus usuarios académicos, haciendo de la cuantificación que odiamos cuando nos la imponen (en Chile, Fondecyt o la propia universidad) algo omnipresente, ineludible y atractiva. Todas o casi todas las páginas del sitio están repletas de cifras, aunque lo más llamativo es la más o menos reciente inclusión de las medidas algorítmicas AuthorRank (el perfil) y PaperRank (el texto), indicadores que en conjunto miden el nivel de "influencia" de un autor. El AuthorRank toma como modelo "al PageRank de Google y al EdgeRank de Facebook, los nombres atribuidos a los dos algoritmos más importantes de la economía web" (Duffy y Pooley: 6). Pronto, todas estas métricas se conectarán para dar lugar a un ranking de los académicos más respetados e influyentes del espacio ciber. Y como si fuera poco, toda esta información está constantemente ingresando a nuestros correos electrónicos 
a través de reportes periódicos que anuncian el movimiento de nuestros indicadores, despertando (produciendo) el deseo de ver cómo aumenta nuestra respetabilidad intelectual.

2. Academia en verdad no es un sitio .edu sino .com, aunque se creó antes de que el uso del .edu fuera normado. Se trata de una startup que opera mediante capital de riesgo, también llamado capital emprendedor. Su modelo de negocios es el de las empresas que cuentan con un gran potencial de crecimiento, como Facebook o Twitter, empresas que surgen a partir de una idea "emprendedora" que se volverá, gracias al uso de la tecnología y la innovación constante, aunque principalmente gracias al crecimiento y trabajo de sus usuarios (nosotros, los "académicos"), en uno de los modelos empresariales más lucrativos. Una de las principales características es que este tipo de empresas surge como una iniciativa que las empresas ya establecidas no apoyarían. No es casual, por tanto, que su creador sea un doctor en filosofía de Oxford, alguien formado para pensar lo que no ha sido pensado, y mucho mejor si esa persona conoce, para el caso que comentamos, la importancia del ego y la autopromoción para el posicionamiento del nombre, esto es, de la propia marca en el mercado de las ideas. "Richard Price, el filósofoempresario que ideó Academia.edu, 6 años después del lanzamiento del sitio, había alcanzado una estrategia ganadora: el automarketing [selfbranding] académico, impulsado por las descargas de artículos" (Duffy y Pooley: 4). Una noticia de 2013, tiene el siguiente título: “Academia. edu, la plataforma de redes sociales para los investigadores, recauda \$11,1 millones". En 2013, contaba con 4,3 millones de usuarios, un gran porcentaje de los supuestamente 17 millones de académicos alrededor del mundo que Price deseaba alcanzar. ${ }^{3}$ Cuatro años después, la empresa cuenta con más de 50 millones de usuarios (50.730.323, al viernes 22 de abril de 2017, a las 00:02 hrs... tres minutos después, se contabilizaba $50.731 .410 \ldots 1087$ usuarios más, 362,33 por minuto, más de seis cada segundo). ${ }^{4}$ Price espera conseguir el perfil y los

${ }^{3}$ https://techcrunch.com/2013/09/26/academia-edu-2/

${ }^{4}$ Hoy, 07 de agosto, a las 00:12 hrs., mientras reviso por última vez este ensayo, Academia.edu registra 53.959.023 usuarios. Por supuesto, la axiomatización no es regular ni tendencial. 
papers de cada académico, con el fin, o con la misión, mejor dicho, de "acelerar la investigación del mundo" de manera libre. Y aquí es donde aparece su anzuelo. En la realización del acceso abierto, Academia.edu contrasta completamente con lo que hacen empresas como Jstor, Elsevier y otras, que cobran precios exorbitantes por descargar artículos. Price se presenta incluso como un filántropo. Lo que no es tan evidente es su modus operandi, pues sus usuarios en realidad son (somos) sus obreros, cuando no su producto. La actividad económica o el crecimiento económico está dado por las actividades que nosotros realizamos, muy similar a Facebook, su principal modelo: nosotros producimos sus contenidos, los compartimos, los promocionamos y los recomendamos, y ahora además nos enviamos saludos y explicamos por qué leemos o descargamos un texto. Y claro, además le sugerimos a colegas y amigos que hagan lo mismo. "Esta confusión usuario / obrero es tan indispensable para Academia.edu como lo es para Instagram" (4), señalan Brooke Erin Duffy y Jefferson D. Pooley en un reciente estudio sobre lo que llamaron el "Facebook de los académicos". Como la plataforma de Mark Zuckerberg, el principal atractivo de Academia.edu es la exposición mediática que le entrega a sus usuarios/autores/productores/ emprendedores. De ahí que el sitio esté constantemente buscando cómo mejorar nuestras formas de auto-marca y autopromoción, contribuyendo así a la producción del modo de subjetividad requerido por la lógica del capital humano. Si ya estamos acosados por la metrología, "menos obvio, tal vez, es nuestra propia internalización de los valores de una cultura de auditoría" (Duffy y Pooley: 7).

3. Bajo este escenario, para quienes nos sustantivamos como intelectuales, y nos adjetivamos además de críticos, quizá sea prudente entrever antes que las formas en que apoyamos a la liberación, los modos en que contribuimos a la servidumbre, por lo general de manera voluntaria. Quizá sea prudente, creo, suspender, así sea momentáneamente, adjetivos y sustantivos, para darle relevancia al adverbio, pues sin preguntarnos por el cómo, por la forma o las formas, es posible adherir e incluso levantar una vanguardia categorial o seguir la "tendencia teórica correcta", sin dejar por ello de abastecer el modo de producción académico, de abastecer la acumulación capitalista. El interés por lo 
que se podría llamar política del adverbio estriba en una inquietud que arrastro, a decir verdad, desde hace varios años. Si se cuenta en "nuestras" filas con nombres como los de Marx, Darwin y Freud, o como los de Beauvoir, Adorno, Fanon, Marcuse, Kate Millett, Foucault, Derrida, Kristeva y un largo etcétera, no me explico cómo entonces nos encontramos habitando un mundo en el que el racismo, la misoginia y la desigualdad radical, por nombrar algunas de las preocupaciones de un intelectual crítico contemporáneo, dominan. Es más, incluso en el momento en que la (supuesta) distancia crítica - esgrimida como un valor clave por la modernidad - se daba por hecho, el intelectual parecía estar más cerca de aquellos por quienes dice preocuparse de lo que podría estarlo hoy, cuando dicha distancia ha desaparecido. Como sociedad, llegamos al siglo Xxi muy pobres en términos de libertades, pero como intelectuales, como intelectuales somos enormemente "privilegiados" si nos comparamos con un Marx en Londres o con un Benjamin en Ibiza, para no mencionar a Gramsci... Pero no todos somos "privilegiados"... la precarización hoy es la norma, dado que la crisis del trabajo también afecta a los "mercados educacionales", gran problema en el que ahora no podemos ahondar, porque aquí interesa esbozar una posible respuesta al problema de la condición intelectual, condición que para este breve ensayo consideraremos a partir de su variante académica, suponiendo que en la Universidad por lo menos una huella de lo que reconocemos como "intelectual" aún sobrevive, así sea de manera espectral. Y para ello recurriremos a Benjamin, una vez más Benjamin, porque este ensayo pretende modestamente ser una relectura, desde la condición académica que nos (me) atraviesa, de "El autor como productor", teniendo en cuenta, como diría Bolívar Echeverría, que la "falta de actualidad de" su

conferencia parece evidente. Se trata de una exposición dirigida a escritores, artistas e intelectuales a quienes, por lo que se desprende de la lectura, parece importarles grandemente el pertenecer o no al bando de la izquierda, el ser o no considerados "revolucionarios"; una especie de interlocutores que no existe ya o de la que quedan sólo unos cuantos ejemplares dispersos, afectados por los estragos de la extemporaneidad y el aislamiento [real y virtual] (96). 
Allí, entre tantas cosas que intentaremos reinscribir en o sobre nuestra contemporaneidad, Benjamin rechaza el logokratischen Aktivismus que pretende el gobierno de los intelectuales. Kurt Hiller, su principal teórico - y entonces un defensor del socialismo y las minorías sexuales - "formula", dice Benjamin, una "crítica de los dirigentes de los partidos", aunque reconoce "[su] sapiencia así como [su] cercanía con el pueblo", "está seguro de una cosa: [esos dirigentes] 'piensan más defectuosamente"" (304). Seamos sinceros: como intelectuales, creemos tener siempre, o casi siempre, la razón. Para eso estudiamos o nos formamos. Nuestro juicio es el más informado y argumentado. Y cuando no lo es, tratamos de que no se note. Por eso Benjamin afirma que es "probable que Hiller tenga mucha razón, pero ¿de qué sirve eso si desde el punto de vista político lo decisivo no es en absoluto el pensamiento privado, sino (como Brecht dijo una vez) el arte de pensar en la cabeza de otras personas?" (304). Y si a ello agregamos que como intelectuales, como intelectuales críticos o radicales por supuesto, buscamos un "lugar junto al proletariado", o buscamos, como diría José Martí, "desestancar al indio" e "ir haciendo lado al negro", entonces estamos transformándonos en "un mecenas en lo ideológico", pero ello implica "un lugar imposible" (305), como sentencia Benjamin, que si tiene razón, ha sido la soberbia y el narcisismo más que la apertura al otro lo que ha enterrado a la teoría crítica, distanciándola de quienes "pretende" liberar.

4. El ahora famoso ensayo citado, para no hablar de la fama misma de Benjamin, especie de rockstar de la teoría crítica contemporánea, pero que cuando lo escribió apenas tenía para vivir (recuerden que por aquellos años trabajaba de manera part-time para la llamada Escuela de Frankfurt, cuna de la teoría crítica), el ensayo, digo, resulta relevante para pensar sobre las condiciones en las cuales, en tanto académicos, intelectuales o críticos, escribimos, pero sabiendo que incluso aquello resulta insuficiente. Pensar esas condiciones implica pensar también los modos de producción, y más específicamente el lugar que ocupamos en él, abasteciéndolo. "El autor como productor" no se preocupa, creo, como Federico Galende cree en su libro Modos de producción, en que los obreros vean a los artistas como ellos, como obreros, sino de que los 
artistas son capaces de verse como obreros. Y no porque artistas como Sergei Tretiakov, al centro de esta lectura de Benjamin, hayan sido capaces de trasladarse a una granja colectiva (koljós) en el Cáucaso Norte, o no sólo por eso. El interés de Benjamin, creo, estriba en recordar que toda actividad intelectual está "condicionada por las relaciones de producción", inmersa en las relaciones de producción, y que, por tanto, desde este punto de vista, radicalmente materialista, el intelectual es un trabajador, un obrero que produce mercancía, un libro, por ejemplo, sobre soberanía y democracia radical o sobre marxismo y literatura, libros que, como mercancía, son producidos por un trabajador que hoy ha devenido emprendedor, esto es, un empresario del saber (de su propio saber) que oblitera su lado fabril. Por ello Benjamin cierra su texto afirmando que "cuanto más exactamente conozca [un académico] su puesto en el proceso de producción, tanto menos se le ocurrirá entenderse en calidad de intelectual" (314). De manera que "El autor como productor" no versa, al parecer, sobre cómo un trabajador puede devenir artista, sino hacer explotar la idea de artista, de autor, de intelectual. Se trata, en síntesis, de abolir la personalidad creativa, pues "esperar una renovación a la manera de estas personalidades [...] es un privilegio del fascismo" (309), dice un Benjamin para quien pensar los modos de producción no sirve de nada si no se busca a la vez transformarlos. Por ello creo que debemos preguntarnos: ¿nuestros libros, nuestros textos, lo que publicamos, lo que producimos, transforma o refuerza la forma de trabajo impuesta por el capitalismo (académico) contemporáneo? ¿Contribuye o cortocircuita el proceso de valorización del capital? Lo pregunto porque si nuestro trabajo se reduce a publicar libros, a dirigir tesis doctorales y/o números monográficos, a organizar paneles en conferencias profesionales, por mucho que todo ello sea hecho en nombre de la deconstrucción más radical de los procesos de acumulación o de la metafísica, y no sólo en nombre, sino verdaderamente luchando contra ello, pero lo hacemos buscando la mejor editorial, el congreso que nos dé mayor visibilidad, dirigiendo las tesis que militarán bajo nuestros conceptos, y todo ello ventilando a través de plataformas virtuales como Facebook o Academia.edu, entonces no habremos hecho nada para transformar el modo de producción académico capitalista. Quizá habremos hecho ruido, que no es poco, pero está lejos de ser 
suficiente. Como señaló Benjamin, “el aparato burgués de producción y publicación puede asimilar y propagar enormes cantidades de temas revolucionarios, sin que su propia subsistencia y la de la clase que lo posee sean por ello puestas en cuestión" (306). Aclaro desde ya, para evitar enemigos, que no pretendo denostar el trabajo del pensamiento, pero éste no puede seguir los canales previamente establecidos, que no han hecho otra cosa que fortalecer la figura del intelectual producida por el capital, que comprendió perfectamente la importancia que le damos a nuestro ego. Benjamin, reitero, muestra la necesidad de quitarse el disfraz de "intelectual", "artista" o "autor" para asumir efectiva y no mentalmente no sólo la lucha obrera, sino la condición obrera, pues como académicos (esto es, como empresarios de nosotros mismos), difícilmente haremos algo más que ruido, lo que, insisto, no es poco, pero está lejos de ser suficiente.

5. Benjamin interroga, por tanto, no la relación entre el intelectual y el obrero, sino entre productores. Sólo así el "autor" se vinculará “con otros productores que antes no tenían mucho que decirle" (307-308). Pero no es fácil quitarse el disfraz. Roberto Bolaño observaba respecto de los escritores contemporáneos una ansiedad que podemos perfectamente encontrar también en los académicos contemporáneos ( $\mathrm{y}$, en verdad, no sólo contemporáneos), una observación que vale la pena recordar aquí:

Los escritores actuales no son ya, como bien hiciera notar Pere Gimferrer, señoritos dispuestos a fulminar la respetabilidad social ni mucho menos un hatajo de inadaptados sino gente salida de la clase media y del proletariado dispuesta a escalar el Everest de la respetabilidad, deseosa de respetabilidad. Son rubios y morenos hijos del pueblo de Madrid, son gente de clase media baja que espera terminar sus días en la clase media alta. No rechazan la respetabilidad. La buscan desesperadamente. Para llegar a ella tienen que transpirar mucho. [...] No es de extrañar que de golpe se sientan cansados. La lucha por la respetabilidad es agotadora. Pero los nuevos escritores tuvieron y algunos aún tienen (y Dios se los conserve por muchos años) padres que se agotaron y gastaron por un simple jornal de obrero y por lo tanto saben, los nuevos escritores [así como los nuevos académicos], que hay cosas mucho más agotadoras que 
sonreír incesantemente y decirle sí al poder. Claro que hay cosas mucho más agotadoras (172-173).

6. Nuestro cansancio entonces resulta, en algún punto, "placentero", pues lo buscamos. Que pasemos semanas promocionando un nuevo libro (he llegado a contar once lanzamientos de un amigo español), o trabajando en el tráiler que lo promocionará; meses viajando para dar conferencias por distintos países, o pasando de un congreso a otro; todo ello, y más, contribuye a afirmar nuestra marca, pues de eso se trata, según el fundador de Academia.edu: "un problema central para los investigadores es cómo construir su marca", afirmó tranquilamente Richard Price en una entrevista. Y si ello es así, nos enfrentamos a un escenario que Benjamin no entrevió, porque de autores nos hemos transformado no en productores, sino en emprendedores, en empresarios de nosotros mismos. Algo, por cierto, que ni Marx previó. De ahí el interés por pensar junto a la teoría del valor, el valor de la teoría, que no es otra cosa que el valor de nosotros mismos. Hasta hace poco, la consigna de la universidad neoliberal era: publica o muere. Ahora, como ya se ha introyectado el placer de la publicación, aunque nos agote, la consigna es: "promuévete o muere". Hasta hace poco, el académico era dueño de su tiempo, ahora el tiempo (del capital) es su amo, con lo cual se niega la capacidad de pensar o investigar rigurosamente, a la vez que se estandariza la escritura, haciendo de ésta un mero medio de información, y por desgracia además no siempre fidedigna.

7. De manera que con el valor de la teoría en realidad me estoy refiriendo al valor que produce el "teórico", pero claro, para eso hay que pasar sí o sí por la teoría del valor, pues ésta, en términos generales, a pesar de considerar la venta del trabajo como una mercancía, operaba, con todo, asumiendo la posibilidad de productos que, bajo determinadas condiciones, podían restarse de la condición de mercancías: "Una cosa puede ser útil, y además producto del trabajo humano, y no ser mercancía", señaló Marx. "Quien, con su producto, satisface su propia necesidad, indudablemente crea un valor de uso, pero no una mercancía" (2008: 50). Para que sea una mercancía, un producto debe entrar en el proceso de intercambio, y hoy la posibilidad de resistirse a dicho 
proceso es (casi) imposible. Satisfacer la propia necesidad es ya valorizarse bajo la lógica del capital humano y quizá aún más para quienes producen mercancías que llevan inscrito el nombre propio. Éste, el nombre propio, es la marca en que cada uno o una se ha convertido bajo la lógica del capital humano, esto es, la transformación de uno mismo en una máquina. Como lo sintetizó Theodore Schultz (1962), se trata de la transformación de cada ser humano en un capitalista o en un emprendedor, cuestión que se logró al transformar el saber en un bien de consumo. Gracias a la teoría del rational choise, se pensó el trabajo no como un proceso, sino como una actividad que, cuando entra en acción, obtiene utilidades; se reintrodujo así el trabajo (intelectual-material) en el análisis económico, y se desdobló en una renta y en un capital; de manera que un sueldo ya no es un salario sino la renta de un capital, y un capital es lo que permitirá recibir ingresos a futuro, un capital que se pone en juego a la hora de entrar al mercado laboral, y que no sólo tiene que ver con el saber, sino también con la idoneidad que se tiene para invertir (en) el propio capital, con las competencias y habilidades, o con los talentos, ${ }^{5}$ de ahí que hoy nuestros "sueldos" dependan de nuestra productividad. Y a ello habría que agregar que hasta los elementos innatos cuentan, razón quizá de la explosión de la ingeniería genética. Y si el capital humano tiene que ver con nuestros genes, con nuestra salud, con nuestro estado físico y/o intelectual, entonces todo aquello que nos permita vendernos de la mejor forma en el mercado académico contribuye a su crecimiento. Ya sea teoría cuántica o deconstrucción, marxismo o feminismo, mientras más profundicemos, aumentaremos nuestro capital y mayores posibilidades de capitalización alcanzaremos, pasando de una universidad de tercera o segunda liga a una de primera, o publicando en una editorial de mayor "prestigio", por ejemplo. En otras palabras, este dispositivo "tratará al saber como capital, aunque un capital algo diferente, pues éste será inseparable de quien lo porte,

${ }^{5} \mathrm{Al}$ respecto, en El nacimiento de la biopolítica, leemos: "Me parece que el interés de esta teoría del capital humano radica en lo siguiente: el hecho de que representa dos procesos; uno que podríamos llamar el adelanto del análisis económico en un dominio hasta entonces inexplorado, y, segundo, a partir de ese adelanto, la posibilidad de reinterpretar en términos económicos y nada más que económicos todo un dominio que, hasta ahora, podía considerarse y de hecho se consideraba como no económico" (Foucault: 255). 
o para decirlo de otra manera, no se lo podrá vender, sin venderse uno mismo en tal transacción, pues está literalmente incorporado; por eso se lo llama capital humano" (rodríguez freire: 108).

8. "Lo que una vez fue la fábrica hoy es la universidad", es lo primero que señala el manifiesto del colectivo Edu-Factory. Ahora bien, si la universidad es una fábrica, entonces produce y su producto, por tanto, no corresponde sólo a libros, publicaciones o patentes, ya que éstos son, de alguna manera, subproductos o derivados (todo ello se puede hacer sin ningún problema fuera de la universidad, y la actual jerarquización en curso que intenta diferenciar jerárquicamente entre profesores e investigadores, lo afirma). Su principal producto es muy concreto: subjetividad, sujetos deseosos de inscribirse en la lógica de la sociedad de la mercancía. Que ya no se aprueben asignaturas sino créditos es un indicio. Que la universidad se gestione a partir del dictum de la llamada Nueva Gestión Pública es otro. Pero que opere bajo los parámetros de un toyotismo articulado junto a un neotaylorismo transforma los indicios en pruebas. Algunos de los procesos del llamado Toyota Production System (TPS), creados para producir autos cada vez mejores, los encontramos en nuestras universidades (como el "mejoramiento continuo", la "satisfacción del cliente", los "procesos de calidad", etc.), cuestión que revela que el saber No es lo principal de la universidad, dado que bajo las actuales condiciones éste no sólo no "mejora", sino que es irrelevante para el modo de subjetividad que se está produciendo.

9. Sin embargo, a pesar de lo señalado hasta aquí, no quiero que se piense que he estado escribiendo desde una posición derrotada o contra la universidad. No. Incluso no creo que el proceso de indiferenciación radical descrito por Marx sea total o que no haya alternativa. La literatura misma es un brazo armado que no se ha podido destruir a pesar de que sobre ella hayan caído todo tipo de armas (incluyendo químicas y nucleares). Se le teme porque la literatura es el arma capaz de inventarle mundos a éste que se nos ha impuesto (le debo esta frase a mi amigo miguel urrutia). Sí creo que quienes operamos como trabajadores y trabajadoras del saber tenemos que pensar y actuar sobre los modos de producción, no en general, sino sobre aquellos que como profesores 
universitarios nos incumben, pues la universidad es el principal terreno de la lucha contemporánea. Exagero. Pero no tanto. Ha sido Willy Thayer quien quizá con mayor acierto ha determinado la centralidad del discurso universitario para el dominio de la sociedad capitalista contemporánea: "la universidad, más que nunca, es el principio de sujeción que produce y se produce como contexto [...] la universidad se ha expandido a los extramuros, borrando ávida y totalitariamente la realidad no universitaria que se le opone o a la que la universidad se opone, ejerciéndose sin piedad, respecto de eso otro no universitario, tipificándolo" (99-100). Para Thayer, "nuestra óptica y modales son universitarios no sólo a causa del sistema educacional directo. No se requiere haber transitado por un currículo específico para estar formateado por la universalidad de la universidad" (98). Desde la parvularia, si es que no incluso desde antes, hasta la publicidad, todo ha sido decidido universitariamente y cada vez más en función de la economía general de la sociedad contemporánea. Ello implica, entonces, que si la universidad constituye un dispositivo nodal para los procesos de acumulación, no hay que verla entonces como un espacio irrelevante sino central para las luchas contemporáneas. Habría que recordar, por lo mismo, que Richard Price, Milton Friedman, Mark Zuckerberg, incluso Trump o Piñera, fueron universitarios. Pero, por otra parte, la ampliación de la matrícula universitaria, así como la proletarización del saber, hacen que la universidad constituya, como otrora la fábrica, un espacio de experimentación política de enorme relevancia. ¿De qué manera? Si la universidad ya no tiene como centro el saber, sino el capital, los estudiantes que hoy se matriculan no adquieren conocimientos sino información. Aquellos guardan la potencia de volverse sobre uno mismo mediante un pliegue que podría transformarnos (a estudiantes y profesores) en sujetos indóciles o desautomatizados. La información, por su parte, se pliega no sobre el sujeto, sino sobre las competencias que lo disciplinarán al servicio del capital. El saber, por tanto, si se toma en serio, es decir, si lo asumimos como una práctica crítica que nos permite interrogar el propio saber, puede abrigar la posibilidad de ser revolucionario, al contribuir a la desujeción de las formas de la verdad que hoy están al servicio del capital. En otras palabras, estudiar lo que más se pueda, y resalto lo que más se pueda, dado que hoy la universidad ofrece cada 
vez menos espacio para ello - de la misma manera que le quita al profesor el tiempo para realizar mejor su trabajo mediante reuniones, autoevaluaciones, programaciones, acreditaciones, etc.- -, apropiándose/ controlando d/el tiempo de las y los estudiantes, estudiar, digo, puede ser verdaderamente revolucionario.

10. Para entrever líneas de fuga me gustaría volver al ensayo de Benjamin y en particular a una de las inflexiones políticas que busca poner en circulación. La que tiene que ver con lo colectivo. "Me gustaría dirigir ahora su mirada", dice Benjamin, "a la obra de Serguéi Tretiakov y al tipo concreto de escritor 'operante' que fue definido y encarnado por él" (300). Dicho tipo de escritor se diferencia del que llama informante, porque mientras el primero tiene como propósito "intervenir activamente", el otro se contenta con observar. Benjamin, creo, se ha centrado en Tretiakov porque su inmersión en un proceso radical de colectivización le llevó incluso a cuestionar su propio rol como "organizador de masas", esto es, como intelectual. Gerald Raunig, quien ha rescatado el trabajo de Tretiakov, señala que su fin era, a partir de la consideración de las diferentes competencias que poseen las personas, "conectar un saber específico con otro saber específico, conformando un mosaico que no tiene por objetivo la completitud, sino más bien configurar una relación de intercambio transversal" (58). Para Benjamin, Tretiakov "permite repensar nuestras ideas sobre las formas o los géneros de la literatura", partiendo por la figura del autor, pues es a partir del escritor ruso como parece haberse escrito "El autor como productor". Ello se evidencia cuando Benjamin ejemplifica las transformaciones que estaba acarreando el periódico en Rusia, donde "el poder escribir ya no se basa en una formación especializada, sino ahora en una politécnica, y así se convierte en bien común". De manera que es a partir de lo común, de lo colectivo, que Benjamin analiza como un revés político la producción de la vanguardia literaria alemana encarnada en la "Nueva objetividad" y el llamado "activismo":

Uno de los acontecimientos decisivos de los últimos diez años en Alemania es que una parte considerable de sus cabezas productivas, presionada por las relaciones económicas, ha desarrollado una mentalidad 
revolucionaria sin estar en condiciones de repensar revolucionariamente su propio trabajo y su relación con los medios de producción, así como su técnica" (Benjamin: 303).

Estas cabezas productivas han resaltado la relevancia de $s u$ lugar en la sociedad, denostando a quienes carecen de su sapiencia. Es más, sin ningún problema han hecho no sólo de la miseria, sino de la lucha misma contra la miseria, un objeto de consumo, empleando para ello la lógica de la moda, que no es otra que la del mercado. Hoy esta situación es común para nosotros, porque incluso conceptos como subalternidad o, más recientemente, precariedad, han llevado al estrellato académico algunos nombres. Por eso hacia el cierre de su ensayo, Benjamin resalta la necesidad de una nueva actitud, ya que es ésta la que le plantea "al escritor una sola exigencia: la de reflexionar sobre su posición dentro del proceso de producción" (314). De manera que Benjamin apuesta por lo común como forma de enfrentar revolucionariamente los medios de producción, todo lo contrario a lo que hoy hacemos como intelectuales, deseosos más que de su transformación, del reconocimiento que nuestros textos puedan recibir en el largo camino hacia la respetabilidad. No somos militantes del saber, sino de nosotros mismos.

11. Pero para quienes habitamos el sur global, no toda referencia a lo común puede convertirse en una estrategia efectiva. Sólo aquella que opera teniendo en cuenta el ámbito de la producción y la división internacional del trabajo podría, eventualmente, constituirse en una posibilidad. Lo señalo porque conceptos como General Intellect se han transformado en moneda de cambio para cierta izquierda, una izquierda que se concentra demasiado en la noción de trabajo inmaterial, un oxímoron, como lo llama Sergio Bologna, ya que el trabajo no puede sustraerse de soporte alguno, por más "intelectual" que sea. En otras palabras, ningún trabajo es inmaterial, ni siquiera, como veremos luego, aquel que produce la tecnología "avanzada" que satisface necesidades que hasta hace poco no teníamos... Y si bien críticos como Virno reparan en lo material, lo hacen de manera insuficiente y problemática. Aunque el límite de esta lectura de lo social y colectivo estriba en la sobrevalorización no sólo del sujeto que se sustantiviza como intelec- 
tual, fortaleciendo innecesariamente el "lugar" tradicional (moderno) del saber, sino que también, aunque no se lo pretenda, se refuerza la ficción de la supuesta potencia que las tecnologías de la información vehiculizarían en pro de la emancipación social. Cuando Maurizio Lazzarato y Antonio Negri (2001) señalaban que "la autonomía del trabajo post-fordista no es intensificación de la explotación, sino ante todo es una intensificación de los niveles de cooperación, del saber y de la comunidad que vacía y deslegitimiza las funciones de comando del emprendedor y del estado", lo hacían con una excesiva confianza depositada en el llamado trabajo inmaterial, inscrito en "el interior de las redes informáticas y telemáticas" del capital contemporáneo. Pero hoy vemos que esa capacidad autónoma de "organizar el propio trabajo y las propias relaciones con la empresa" no han contribuido a la liberación sino a la profundización de la explotación, aunque ahora por mano propia, pues esa autonomía ha devenido empresarización de sí. Como señalara irónicamente Robert Kurz, las personas ocupadas en el comercio de los símbolos y la información "de ninguna manera constituyen una multitud"; a nivel global son una verdadera minoría.

Esto se debe a que la microelectrónica, que volvió superfluo el trabajo industrial, no produce ningún nuevo trabajo capitalista masivo. Tras los modelos de procesamiento de información, de comunicación y de analítica simbólica, ya no están encadenados millones de trabajos secundarios de acabado, como en las industrias fordistas, sino procesos tecnológicos automáticos, máquina de comunicación y medios que sólo necesitan de los seres humanos en tanto consumidores (Kurz).

Esto dificulta los procesos reales de acumulación (esto es, no hay subsunción real), produciéndose así la actual crisis del trabajo. ${ }^{6}$ Habría que recordar, por tanto, que el "trabajo inmaterial", de realizarse, se da principalmente en emprendedores autoexplotados que ven en su supuesta independencia del taller un modo de liberación del trabajo abstracto, sin percibir que su trabajo concreto es una mera ficción. Víctimas del "outsourcing" (reducción de personal), el trabajador "autónomo" (o boletariado), incluyendo aquí a las y los profesores contratados por horas,

${ }^{6}$ Al respecto, ver Kurz 2016; Jappe 2015; y Grupo Krisis 2002. 
es en verdad un "empresario" que gestiona su propia y muy material precariedad.

12. De manera que dos son las dificultades de esta noción que opera como forma de lo común, aunque podríamos agregar una tercera, que ya revisaremos. Según Paolo Virno, "compartir aptitudes lingüísticas y cognitivas es el elemento constitutivo del proceso laboral postfordista" (41) que la noción de intelecto general encarna, y luego agrega que ésta "se presenta hoy antes que nada como comunicación, abstracción, autorreflexión de sujetos vivos [...]. Dicho en otros términos, el intelecto público se identifica con la cooperación, con el actuar concertadamente del trabajo vivo, con la competencia comunicativa de los individuos" (66). El problema con esta descripción es, aparte de equiparar trabajo vivo con trabajo inmaterial, no sólo que se distancia bastante de lo que Marx refería con intelecto general, sino que además la desmaterializa borrando la distinción entre trabajo productivo e improductivo (tal como hace Garey Becker y su teoría del capital humano), sin contar que para Marx todo trabajo es, como el capital, siempre y necesariamente social, más allá de la competencia lingüística: la producción material es "el verdadero proceso de la vida social", señala en el famoso Capítulo VI inédito (2008: 19) de El Capital. El absurdo que se puede generar respecto a lo social no radica o no radica sólo en que hoy, y no en los años en que Marx intentaba comprender la fuerza destructiva del capitalismo, se piense el trabajo como cooperación. Al contrario, lo absurdo para Marx estriba en que "determinadas relaciones de producción sociales entre personas se presentan como relaciones entre cosas y personas, o determinadas relaciones sociales aparecen como cualidades sociales que ciertas cosas tienen por naturaleza" (38). Por otra parte,

7 Más adelante, Marx deja en claro cómo opera la sociedad capitalista y la forma en que emplea los medios de producción: "medios y materiales de trabajo se emplean colectivamente, y esta utilización colectiva tiene como premisa absoluta la cooperación de obreros asociados, y por tanto ella misma no es más que la expresión objetiva del carácter social del trabajo y de la fuerza productiva social que de ello resulta, así como en su mayor parte la forma particular de estas condiciones - por ejemplo como maquinaria - no es aplicable fuera del trabajo asociado. Sin embargo, frente al obrero que entra bajo las mismas, esas condiciones se presentan como dadas e independientes de él, como forma del capital" (95). 
la autonomía para Marx no se da en el trabajo de un sujeto independiente, sino precisamente en un trabajo colectivo que se sustrae (y que debiera sustraerse) a la lógica de la mercancía, un trabajo como el desarrollado por los gremios artesanales, dado que estos constituían "una forma limitada, inadecuada aún, de la relación del capital y del trabajo asalariado" (65). La relevancia de lo común se encuentra en varios momentos de la reflexión de Marx y resuena claramente hacia el final de su vida, particularmente en la carta que en 1881 le envió a Vera Zasúlich, donde señala que "el estudio especial que de ella he hecho [se refiere a la comuna rural, a la que también llama propiedad común], y cuyos materiales he buscado en las fuentes originales, me ha convencido de que esta comuna es el punto de apoyo de la regeneración social en Rusia", pero no sólo para Rusia:

La mejor prueba de que este desarrollo de la "comunidad rural" responde al rumbo histórico de nuestra época es la crisis fatal que experimenta la producción capitalista en los países europeos y americanos, en las que se ha desarrollado más, crisis que terminará con la eliminación del mismo, con el retorno de la sociedad moderna a una forma superior del tipo más arcaico: la producción y la apropiación colectivas (1980a: 41).

Si bien es errado el diagnóstico de Marx, no lo es, creo, su apuesta por "la producción y la apropiación colectivas". Es cierto que el capital ya produce colectivamente, pero no ocurre lo mismo con la apropiación de la producción social, que opera fundamentalmente de manera privada. Es más, el Copy Right, por ejemplo, es una forma ficticia, pero no por ello menos real, de cercar el saber colectivo, de apropiárselo individual y comercialmente. En síntesis, el intelecto público no es una cuestión del presente, sino la base de toda sociedad, cuando no de la humanidad misma. El problema es, como veremos luego, la lectura errada de Marx por parte de Virno y otros.

13. Revisemos el famoso fragmento donde Marx emplea la noción de General Intellect. ${ }^{8} \mathrm{Me}$ interesa resaltar en particular lo que se encuentra

${ }^{8}$ Es cierto, como ha resaltado Virno, que General Intellect se encuentra en inglés, pero dudo que ello sea, como afirma, "para dar[le] fuerza a la expresión, como si quisiera 
tan sólo unas líneas antes y es lo siguiente: "La naturaleza no construye máquinas, ni locomotoras, ferrocarriles, electric telegraphs, selfacting mules, etc. Son éstos, productos de la industria humana: material natural, transformado en órganos de la voluntad humana sobre la naturaleza o de su actuación en la naturaleza. Son órganos del cerebro humano creados por la mano humana; fuerza objetivada del conocimiento" (2008: 229-230. Énfasis de Marx) [Sie sind von der menschlichen Hand geschaffne Organe des menschlichen Hirns]. Creo que si aquí Marx quiere resaltar algo no es tanto el intelecto general (ni el intelecto en general) como la imbricación entre pensamiento y técnica, entre cerebro y mano, "hombre" y "naturaleza". Fíjense que las máquinas son para él órganos, afirmación que recuerda indefectiblemente al trabajo del paleontólogo André Leroi-Gourhan, quien en El gesto y la palabra señala que la herramienta es "una verdadera secreción del cuerpo y del cerebro de los antrópidos", aunque su tesis más radical es aquella que afirma que sin herramienta no existiría eso que hoy llamamos "hombre". Es lógico, concluye Leroi-Gourhan, "aplicar a un tal órgano artificial [la herramienta o la máquina] las normas de los órganos naturales" (93). Ello implica que el desarrollo o evolución de la técnica sigue la de los humanos, y viceversa. Un verdadero acoplamiento estructural que nos

ponerla en cursivas" (ya que no lo está), pues en el mismo fragmento también aparecen en inglés electric telegraphs, selfacting mules, fixe y knowledge, y dudo que fixe o telegraphs sean palabras que necesiten alguna fuerza expresiva; es más, en el fragmento inmediatamente anterior Marx injerta otras que también están en inglés, como powerful effectiveness, In fact, Wealth, lo cual hace evidente que no por ello resultan fundamentales, cuestión, por cierto, que se refuerza cuando leemos "question de vie et de mort". Lo que Marx resalta, por el contrario, son otras palabras, y esas están en alemán. Por otra parte, en El capital, encontramos expresiones en latín, griego y francés, además de inglés... de manera que escribir General Intellected (así como muchos otros términos, expresiones, etc.) en lugar de intelecto general tiene que ver, quizá, con explicitar el cruce de las mercancías entre fronteras lingüísticas y de otros tipos, pues sus escritos, y eso es algo que Marx sabía perfectamente, "adquieren valor a medida que se van moviendo entre mercados, lenguajes y marcos expresivos" (Lezra: 132) diversos. Así que posiblemente la noción de General Intellected, que no ha sido empleada en ningún otro lugar por Marx, tiene la función, sólo en el fragmento y a manera de paradoja, de reforzar el palpable hecho, la obviedad, si se quiere, de que todo conocimiento es siempre colectivo, de ahí que también refiera el "knowledge social general". En otras palabras, como señalaría Jacques Lezra, el inglés operaría sólo para darle al conocimiento social "valor de uso corriente". 
impide privilegiar el cerebro, un pensamiento cyborg como muy bien recuerda el ensayo de Engels, El papel del trabajo en la transformación del mono en hombre, donde señala que "gracias a la cooperación de la mano, de los órganos del lenguaje y del cerebro, no sólo en cada individuo, sino también en la sociedad, los hombres fueron aprendiendo a ejecutar operaciones cada vez más complicadas, a plantearse y a alcanzar objetivos cada vez más elevados" (264). No es posible pensar el trabajo intelectual sin la materialidad del cuerpo y los órganos que éste secreta. Además, como afirmó Leroi-Gourhan, la condición humana no comenzó por la cabeza, sino por los pies, porque ellos permitieron la liberación de la mano y ésta es la que dio "acceso al arte, al artificio y a la techné" (Stiegler: 171). Sin mano que se une a otras manos sencillamente no hay creación, no hay pensamiento. Sin unas manos que puedan manipular lo que les rodea y, al hacerlo, simbolizar a su vez eso que les rodea, seríamos simples animales.

14. Por eso es que la idea de trabajo inmaterial es un oxímoron que no contribuye a la comprensión del lugar que el saber ocupa en los modos de producción (un saber hoy completamente proletarizado), y lo peor es que parece confundírselo con la idea de trabajo abstracto; es cierto que con lo que aquél se nombra podría coincidir, pero no son los mismo. Es más, si se revisa el primer tomo de las Teorías sobre la plusvalía, se verá que no es una noción que Marx acepte de buenas a primeras, y es crítico de quienes la usan como sinónimo de trabajo improductivo (1980b: 194, 244, 380). Pero lo más relevante para nuestra discusión es que la noción de trabajo inmaterial otorga una prioridad injustificada tanto a lo intelectual, así como a lo comunicativo y lo inmaterial (Hardt y Negri: 50), obliterando lo que ocurre en los países que producen la tecnología con la que trabajamos quienes nos sustantivamos como "intelectuales". Creo que el postobrerismo acertó al referir la centralidad del trabajo postfordista, así como el lugar que en él tiene la subjetividad, pero una nueva teoría del valor debe formular algo más que "una nueva teoría de la subjetividad que opere principalmente a través del conocimiento, la comunicación y el lenguaje" (Hardt y Negri: 50), ya que, insisto, el trabajador autónomo no ha dado lugar a un sujeto colectivo, sino a uno atomizado, como mostró muy bien Jaron Rowan en Emprendizaje en 
cultura (2010), libro en el que afirma que los autónomos de la cultura (trabajadores inmateriales) constituyen un modo de subjetivación que opera contra lo común: "este fenómeno incentivaba el proceso de privatización de las actividades culturales según una lógica de cercamiento de dinámicas, prácticas y saberes colectivos" (37). Por eso me gustaría revisar unos poemas de Xu Lizhi, un trabajador de Foxconn, la empresa encargada de ensamblar en China el iPhone que usa el General Intellect del norte. Uno de sus textos se titula "Me quedo dormido, incluso estando de pie" y es de una radicalidad que merece ser citada en extenso:

Frente a mis ojos la hoja se vuelve amarillenta, Con una pluma de acero tallo un negro desigual Repleto de palabras del trabajo [working words] Taller, línea de ensamble, máquina, tarjeta de registro, horas extras, salarios...

Me entrenaron para ser dócil

No sé cómo gritar o rebelarme, cómo quejarme o denunciar, sólo sé sufrir silenciosamente este agotamiento.

Cuando pisé por primera vez este lugar

Sólo esperaba el cheque gris del diez de cada mes.

Para concederme algún consuelo tardío

Me encadeno a mi esquina y a mis palabras.

Renuncio a faltar al trabajo, rechazo las licencias médicas, renuncio a faltar por razones personales

Me niego a llegar tarde, me niego a salir temprano.

En la línea de ensamble me mantengo firme como el hierro, y mis manos vuelan.

¿Cuántos días, cuántas noches — tal cual— me quedé dormido estando de pie?

(20 de agosto de 2011)

Xu Lizhi se suicidó el 2014, a la edad de 24 años, lanzándose de su dormitorio/departamento, ubicado en el piso 17 de un edificio de Shenzhen. Su muerte, como la de miles de migrantes, es una de las cientos que acometen anualmente trabajadores del capitalismo "inmaterial". Otro de sus poemas se titula "Taller, Mi Juventud se estancó aquí", mientras 
que algunos de los versos de otros escritos describen cómo opera la empresa que ensambla los teléfonos del General Intellect: "En cuanto ingresas al taller / la única opción es la sumisión"; "Observar que eres molido día y noche / Presionado, pulido, moldeado / Por unos cuantos míseros billetes, a los que llaman salario". El anticipo de su porvenir es "Un tornillo cayó al suelo":

Un tornillo cayó al suelo

En esta noche oscura de horas extras

Sumiéndose verticalmente, tintineando ligeramente

Nadie le prestará atención

$\mathrm{Al}$ igual que la última vez

En una noche como esta

En la que alguien se lanzó al vacío. ${ }^{9}$

Para que nadie más caiga como un tornillo es que a estos productores de nanotecnología incluso se les está negando la posibilidad del suicidio, clausurando las ventanas de sus nanodepartamentos, si así se puede llamar a los 10 metros cuadrados en los que sobreviven. De manera que los defensores del intelecto general, que no han considerado este hecho, no sólo sobrevaloran el lugar de la intelectualidad, sino que, al obliterar lo que la hace posible, niegan la explotación radical de aquellos que no viven en Silicon Valley. De ahí que incluso la idea misma de "lugar del intelectual" sea una forma de la cual hay que tomar distancia, para comenzar a pensar más bien en el carácter productivo y material del saber en su vínculo con las manos. Por ello es radical el texto de Benjamin, al conminarnos a superar la forma burguesa de la producción espiritual, centrada en la figura del autor. Sabemos que la actual crisis del trabajo también afecta a las universidades, cuya gestión es homónima a la de cualquier empresa. Esta crisis expulsa a los trabajadores de las fábricas, transformando a cada extrabajador en un emprendedor que debe competir de manera autónoma no por la cooperación, sino por su sobrevivencia. Pero esta "desproletarización" del trabajo fabril corre

${ }^{9}$ He tomado los poemas de la siguiente página: < https:/www.poesiacastellana.es/ general-publisher/8721-poes\%C3\%ADa-y-breve-vida-de-un-trabajador-de-foxconnxu-lizhi.html>. 
paralela a la proletarización del trabajo académico, sólo que, como recordó Benjamin, "la proletarización del intelectual casi nunca tiene por resultado un nuevo proletariado. ¿Por qué? Porque la clase burguesa le ha dado al intelectual mediante la cultura un medio de producción que, a consecuencia del privilegio cultural, lo hace estrictamente solidario con ella, y aún más todavía a ella con él" $(314),{ }^{10}$ razón quizá por la cual el autónomo que exaltaban Lazzarato y Negri se transformó en un emprendedor que rechaza su componente laboral, ya que reconocerlo implicaría verse como obrero antes que como capitalista.

15. Esta dificultad que entrevió Benjamin quizá estribe en que como intelectuales o académicos hemos terminado adoptando con demasiada facilidad el modelo de sociedad forjado por la forma dinero y el fetiche de la mercancía, modelo que le ofrece al autor la ficción de rescatarlo del "trabajo humano indiferenciado" (abstracto), consignando su nombre (concreto) sobre todo lo que escriba/produzca. De manera que el lugar del intelectual está articulado cada vez más no con lo común, sino con las patentes o el Copy Right — dispositivo que el capital emplea para individualizar y así valorizar el saber-. Si nos preocupa la universidad como espacio de discusión y producción del saber, de un saber que favorezca a la sociedad y no a un grupo de empresas, el intelectual crítico debe preguntarse seriamente cómo está en las relaciones de pro-

${ }^{10}$ Esta sentencia benjaminiana se ajusta muy bien a una afirmación similar dada por Marx en Las teorías de la plusvalia: "tan pronto como la burguesía ha conquistado el terreno y, en parte, se adueña del Estado y, en parte, llega a un arreglo con los viejos titulares de éste, reconociendo a los estamentos ideológicos [esto es, a los "intelectuales" contra los que poco antes enfrentó] como carne de su carne y convirtiéndolos por doquier en sus propios funcionarios acomodándolos [a sus intereses]; tan pronto como ya no se considera la representante del trabajo productivo frente a estos [elementos], sino que los verdaderos trabajadores productivos se levantan en contra de ella misma y la acusan de vivir también del trabajo de otros; tan pronto como la burguesía es lo suficientemente cultivada para no dejarse absorber por la producción y aprende a consumir también de un modo 'culto'; tan pronto como los trabajos intelectuales se ejecutan también más y más al servicio de ella, al servicio de la producción capitalista, se vuelve la hoja y la burguesía trata de justificar 'económicamente' desde su propio punto de vista lo que combatía críticamente" (1980b: 278). En otras palabras, lo que los intelectuales hacen en el nuevo escenario dominado por la lógica del capital es justificar a la burguesía ascendente, para que así ésta, a modo de "gratitud", les justifique sus salarios. 
ducción, con el fin de interrumpir la apropiación de lo común por parte del capital, y ponerlo al servicio de la humanidad. En otras palabras, debemos publicar en espacios que se sustraigan a la valorización privada y comercial, espacios que habrá que inventar colectivamente, ya que la rigurosidad del trabajo que hacemos no puede continuar secuestrada por los falaces indicadores que promete la indexación. El saber, lo sabe muy bien aquella o aquel a quien "la dicha y el juego le son esenciales" (Adorno: 12) y lo consideran una forma de vida, no es indexable. Lo que nos resta, por tanto, es una verdadera batalla, porque a la par que levantemos nuevas plataformas para la circulación del saber, tendremos que demostrar el daño que la estandarización le ha hecho a la universidad y a la humanidad en general. Esta batalla sólo puede tener éxito si se trabaja en común y para el común, borrando, si es necesario, nuestro propio lugar - ese lugar que el capital inventó para nosotros-, escribiendo para perder el rostro... y el nombre.

\section{BIBLIOGRAFÍA}

Adorno, THEOdor W. "El ensayo como forma", en Notas sobre literatura. Trad. Alfredo Brotons. Madrid: Akal, 2009.

Benjamin, Walter. "El autor como productor", en Obras, libro II/vol. 2. Trad. Jorge Navarro Pérez. Madrid: Abada, 2009.

Bolaño, Roberto. "Los mitos de Cthulhu", en El gaucho insufrible. Barcelona: Anagrama, 2003.

Borges, Jorge Luis. "Tlön, Uqbar, Orbis Tertius", en Obras completas I. Ed. crítica. Buenos Aires: Emecé, 2009.

Duffy, Brooke Erin y Jefferson D. Pooley. "Facebook for Academics: The Convergence of Self-Branding and Social Media Logic on Academia. edu", en Social Media + Society (2017).

ECHEVERría, Bolívar. "El autor como productor", en Siete aproximaciones a Walter Benjamin. Bogotá: Desde abajo, 2010.

Edwards, Marc y Siddhartha Roy. "Academic Research in the 21st Century: Maintaining Scientific Integrity in a Climate of Perverse Incentives and Hypercompetition", en Environmental Engineering Science 34.1 (2017).

Engels, Friedrich. El papel del trabajo en la transformación del mono en hombre. Buenos Aires: Godot, 2014.

Foucault, Michel. El nacimiento de la biopolítica. Trad. Horacio Pons. Buenos Aires: Fondo de Cultura Económica, 2007. 
Hardt, Michael y Antonio Negri. Empire. Cambridge: Harvard University Press, 2000.

Jappe, Anselm, Jordi Maiso y José Manuel Rojo. Criticar el valor, superar el capitalismo. Madrid: Enclave, 2015.

Krisis. Manifiesto contra el trabajo. Barcelona: Virus, 2002.

Kurz, Robert. “O complexo de Harry Potter", en Folha de S. Paulo, 30 de octubre de 2005. Artículo en línea disponible en $<$ http://www1.folha.uol.com. $\mathrm{br} / \mathrm{fsp} / \mathrm{mais} / \mathrm{fs} 3010200515 . \mathrm{htm}>$ [fecha de consulta: 9 de agosto de 2017]. Kunz, Robert. El colapso de la modernización. Buenos Aires: Marat, 2016. Lazzarato, Maurizio y Antonio Negri. Trabajo inmaterial. Formas de vida y producción de subjetividad. Río de Janeiro: DP\&A Editora, 2001.

Leroi-Gourhan, André. El gesto y la palabra. Trad. Felipe Carrera. Caracas: Universidad Central de Venezuela, 1971.

LeZRA, JACQues. "Soberanía o traducción: las decisiones de Sancho", en El lugar de la literatura en el siglo XXI. Valparaíso: Dársena/EUV, 2016.

MarX, Karl. Escritos sobre Rusia II. El porvenir de la comuna rural rusa. México: Pasado y Presente, 1980a.

Marx, Karl. Teorías sobre la plusvalía, vol. 1. Trad. Wenceslao Roces. México: Fondo de Cultura Económica, 1980b.

Marx, Karl. El capital. Libro 1. Capítulo sexto (inédito). Trad. Pedro Scaron. Buenos Aires, Siglo XXI, 2008.

RAUnig, GeRALD. "Transformar el aparato de producción", en Gustav Klucis. En el frente del arte constructivista. Sevilla: Cajasol Obra Social, 2009.

RODRÍGUEZ FReIRE, RAÚL. "Capital humano", en Mary Luz Estupiñan (ed.). El abc del neoliberalismo. Viña del Mar: Communes, 2016.

RowAn, JARON. Emprendizaje en cultura. Madrid: Traficantes de Sueños, 2010. Schultz, Theodore. "Reflections on Investment in Man", en Journal of Political Economy, 70: 1-8, 1962.

Stiegler, Bernard. La técnica y el tiempo 1. El pecado de Epitemeo [1994]. Trad. Beatriz Morales. Hondarribia: Argitaletxe Hiru, 2002.

THAYER, WILLY. "La crisis no moderna de la universidad moderna", en El fragmento repetido. Santiago: Metales Pesados, 2006.

Virno, Paolo. Gramática de la multitud. Madrid: Traficantes de sueños, 2003.

RAÚL RODRÍGUEZ FREIRE

Doctor en Literatura. Profesor de la Pontificia Universidad Católica de Valparaíso. Investiga sobre narrativa latinoamericana contemporánea, crítica y teoría literaria y transformaciones universitarias. Entre sus publicaciones, se encuentran las coediciones de Descampado. Ensayos sobre las contiendas universitarias (2012) y Crítica literaria 
y teoría cultural en América Latina. Para una antología del siglo XX (2015, 2018 segunda edición), además de una edición crítica dedicada a la obra de Roberto Bolaño, titulada "Fuera de quicio". Bolaño en el tiempo de sus espectros (2012) y la edición de Latinoamericanismo a contrapelo. Ensayos de Julio Ramos (2015). También coeditó y tradujo Una literatura en los trópicos. Ensayos de Silviano Santiago (2012; 2017), Figuras de la violencia, del crítico Idelber Avelar (2016), y Erich Auerbach y Walter Benjamin. Correspondencia $(2014,2015)$. Sin retorno. Variaciones sobre archivo y narrativa en Latinoamérica (2015) es su último libro. 